\title{
CORRELATIONS BETWEEN SERUM BETA 2 MICROGLOBULIN LEVELS, DISEASE ACTIVITY AND CONVENTIONAL BIOMARKERS IN PATIENTS WITH PRIMARY SJÖGREN'S SYNDROME
}

\author{
Isabela Botelho Maciel Bueno1,*, Maria Carolina Oliveira1, Fabíola Reis Oliveira1 \\ 1.Universidade de São Paulo, Ribeirão Preto (SP), Brazil. \\ ${ }^{\star}$ Corresponding author: isabelabmb@yahoo.com.br
}

\section{BACKGROUND}

Primary Sjögren's syndrome (pSS) is an autoimmune disease associated with extra glandular manifestations and possible lymphoma transformation. Biomarkers ( $\mathrm{C} 4$ consumption, hypergammaglobulinemia, cryoglobulins) are predictive for these disease manifestations. Beta 2 microglobulin (B2M) is a protein that indicates activation of immune cells, and may be used as a marker for hematologic neoplasms and renal dysfunction. The behavior of serum B2M levels is not well defined in Sjögren's syndrome. This study aimed to evaluate B2M levels in pSS patients, and how they correlate with traditional indicators of disease activity and prognostic biomarkers.

\section{METHODS}

This is a cross-sectional analytical study conducted at the rheumatology outpatient clinic of a university hospital. One hundred patients with pSS were evaluated for disease activity indices (ESSDAI and EPSSRI) and B2M levels and compared to other biomarkers (gamma globulin fraction of protein electrophoresis, C3 and C4 serum levels and presence of cryoglobulins).

\section{RESULTS}

One hundred patients were evaluated, $97 \%$ female, mean age of $51.84 \pm 13.8$ and mean disease duration of $5.85 \pm 5.35$ years. Thirty-six percent (36/100) of the patients were obese, $9.1 \%(n=9 / 99)$ had kidney disease and $2 \%(2 / 100)$ had a confirmed diagnosis of lymphoma. Eighty-two percent had positive anti-SSA/Ro antibodies and $90 \%$ a focus score $\geq 1$ ( $n=80 / 89$ ). Serum B2M levels were increased in $48.4 \%(n=47 / 100)$ of cases. There was a positive correlation of B2M serum levels with disease activity measured by ESSDAI $(p=0.001)$ and the EPSSRI $(p=0.05)$. In the ESSDAI, the agreement was greater between B2M levels and the renal and biological domains of the instrument. There was also a positive correlation between B2M and gamma globulin serum levels $(p=0.006)$. There were no correlations between B2M and autoantibodies (Ro, La, ANA, presence of cryoglobulins, C4 levels or focus scores). The two patients with lymphoma had B2M serum levels of 2062 and $2841 \mathrm{ng} / \mathrm{mL}$ at diagnosis of the malignancy, within the normal range.

\section{CONCLUSION}

Beta 2 microglobulin serum levels are elevated in pSS patients with active disease, especially in those with higher scores in the renal and biological domain of the ESSDAI, and in patients with hypergammaglobulinemia.

\section{KEYWORDS}

Sjögren's syndrome, Beta 2 microglobulin, Biomarkers, Disease activity. 